\title{
Genomic organization of the MTM1 gene implicated in X-linked myotubular myopathy
}

\author{
J ocelyn Laporte ${ }^{1}$, Christophe G uiraud-Chaumeil ${ }^{1}$, Stephan M Tanner ${ }^{2}$, François \\ B londeau ${ }^{1}$, L ing-J ia H ${ }^{1}$, Serge V icaire ${ }^{1}$, Sabina L iechti-G allati ${ }^{2}$ and J ean-L ouis M andel ${ }^{1}$ \\ ${ }^{1}$ Institut de G énétique et de Biologie M oléculaire et Cellulaire, CNRS, Illkirch Cedex, France \\ ${ }^{2}$ D epartment of Clinical Research \& D epartment of Pediatrics, U niversity of B erne-Inselspital, B erne, Switzerland
}

\begin{abstract}
$X$-linked recessive myotubular myopathy (XLMTM) is a very severe congenital muscular disease characterised by an impaired maturation of muscle fibres, and caused by defects in the MTM1 gene. This gene defines a new family of putative tyrosine phosphatases conserved through evolution. We have determined intronic flanking sequences for all the 15 exons to facilitate the detection of mutations in patients and genetic counselling. We characterised a new polymorphic marker in the immediate vicinity of the gene, which might prove useful for linkage analysis. Sequencing of the TATA-less predicted promoter provides the basis for transcriptional regulatory studies.
\end{abstract}

Keywords: myotubular myopathy; promoter; genomic structure; linkage; MTM1; tyrosine phosphatase

\section{Introduction}

$X$-linked recessive myotubular myopathy (XLMTM OMIM 31040) is a very severe congenital muscular disease characterised by hypotonia and generalised muscle weakness in newborn males. Most patients die within the first months of life. Characteristic muscle histopathology consists of small rounded muscle cells with centrally located nuclei resembling foetal myotubes and it has been suggested that the disorder results from an arrest in the normal development of muscle fibres, probably during late myogenesis. ${ }^{1}$ The locus responsible for the disease (MTM 1 ) was mapped to proximal $\mathrm{Xq28}$ by linkage analysis and the candidate

Correspondence: J ean-L ouis $M$ andel, IG B M C, 1 rue $L$ aurent Fries, BP163, 67404 Illkirch Cedex, France. Tel: (33) 3886532 44. Fax: (33) 3886532 46. E-mail: mtm@igbmc.u-strasbg.fr R eceived 26 September 1997; revised 22 December 1997; accepted 24 December 1997 region was restricted by analysing recombination events and patients carrying deletions. ${ }^{2,3}$ We have recently reported the identification of the MTM 1 gene by positional cloning. ${ }^{4}$ It encodes a protein (myotubularin) with a putative tyrosine phosphatase domain (PTP). Tyrosine phosphatases have been shown to be involved in transduction pathways controlling cell growth and differentiation. ${ }^{5}$ Myotubularin is highly conserved through evolution and several homologous human genes were found, which define a new family of putative tyrosine phosphatases in man.

In this study we have determined the complete exonintron structure of the human M TM 1 gene and $2.7 \mathrm{~kb}$ of upstream sequences in $5^{\prime}$. This information is very useful for the characterisation of mutations in X L M TM patients, a prerequisite for reliable genetic counselling and determination of carrier status. ${ }^{6}$ A new polymorphic marker, located less than $3 \mathrm{~kb}$ upstream from the MTM 1 gene, may allow a more reliable linkage analysis in familial cases. 


\section{Materials and Methods}

Four cosmids (ICRF C104-H 05147, C 104-E 03147, C 104-B 03151 and a X q28 specific library cosmid Q c3A 3) were subcloned as described. ${ }^{3}$ Subclones were screened by hybridisation with radioactively labelled CD NA s or oligonucleotides, and by PCR, for the presence of M TM 1 exons and further sequenced with exon specific primers. A s exons 5 to 8 were not included in our cosmid contig, PCR and long-range $P C R$ from genomic DNA was performed with exonic primers, to clone introns 4, 5, 6, 7 and 8. For long-range $P C R$ analysis of intron sizes, $300 \mathrm{ng}$ of genomic DNA was amplified using the Expand Long Template PCR System kit (Boehringer $M$ annheim, M eylan, France) for 30 cycles with an elongation time ranging from 4 to 15 minutes, and to assess their size more precisely each product was digested with $\mathrm{Bam} \mathrm{HI}, \mathrm{Cla} \mathrm{I}$, $\mathrm{H}$ pa I, Pvu II and Sac I and compared to size marker (from B oehringer $M$ annheim, M eylan, France) (Figure 1 ). L ongrange PCR was unable to amplify intron 1 and its size was estimated from hybridisation experiments using specific probes from exons 1 and 2 on the previously characterised cosmid contig, digested with $\mathrm{Bam} \mathrm{HI}$ and Bgll or EcoRI. E xon 1 is present in cosmid Q C3A 3 from a X q28 library, while exon 2 is present in the overlapping cosmid C104-B 03151 from $L$ awrence Livermore National Laboratories. ${ }^{3}$

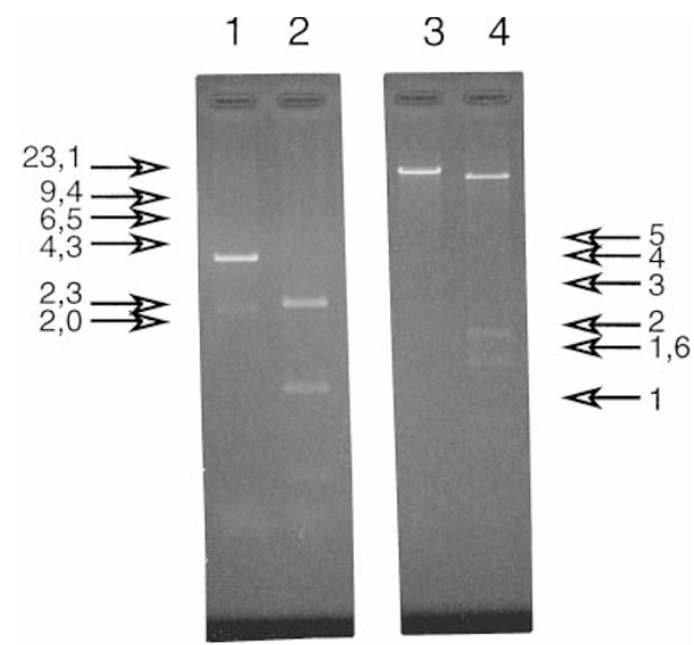

Figure $1 L$ ong range $P C R$ analysis of the size of introns 2 and 6 . Long range $P C R$ was performed as described in methods using exon specific primers VN 14 ( $5^{\prime}$ A G A A C C T $G$ TA A A G T A G T A C C $\left.3^{\prime}\right)$ and $V C 113$ (5'AGACTTCTCCTCAAGTTATGC $3^{\prime}$ ) for intron 2 (annealing at $52^{\circ} \mathrm{C}$ with a 4 min elongation step) and GT003 (5'CTCACGAGATACGCGTTTC $3^{\prime}$ ) and TW57 (5'CT G CCTCCTG TATTCTTCC $3^{\prime}$ ) for intron 6 (annealing at $56^{\circ} \mathrm{C}$ with a $15 \mathrm{~min}$ elongation step). PCR fragment sizes were estimated on a $0.8 \%$ agarose gel either undigested and after digestion with $\mathrm{H}$ pal, Pvull, and Sacl (the latter two are not shown). L ane 1 and 2 correspond to intron 2 (undigested and $\mathrm{H}$ pal digested respectively) and lane 3 and 4 the corresponding products for intron 6 . Size markers are in the exterior lane. Size of intron 2 and intron 6 were estimated at $3.8 \mathrm{~kb}$ and $20.4 \mathrm{~kb}$ respectively.
A polymorphic CA repeat was characterised in the putative promoter sequence at position -2624 to -2587 of the sequence in Figure 2. B riefly, $100 \mathrm{ng}$ of patient DNA were amplified in $10 \mathrm{mM}$ tris- $\mathrm{HCl} \mathrm{pH} 8.3,50 \mathrm{mM} \mathrm{KCl}, 200 \mu \mathrm{m}$ dNTP, $1.5 \mathrm{mM}$ $\mathrm{M} \mathrm{gCl}_{2}$, with 10 pmoles of each primers, 1 nmole $(3 \mu \mathrm{Ci})$ of ${ }^{32} \mathrm{P}$ dCTP and 1 unit of Taq polymerase in a total volume of $25 \mu \mathrm{l}$. Thermocycling was carried out in the PT C-100 Programmable Thermal Controller (M J Research, Inc., USA) at $94^{\circ} \mathrm{C}$ for 5 min followed by 30 cycles at $94^{\circ} \mathrm{C}$ for $10 \mathrm{~s}, 53^{\circ} \mathrm{C}$ for $10 \mathrm{~s}, 72^{\circ} \mathrm{C}$ for $10 \mathrm{~s}$, and a final elongation step at $72^{\circ} \mathrm{C}$ for $5 \mathrm{~min}$. A fter $\mathrm{PCR}$, the products were denaturated at $94^{\circ} \mathrm{C}$ for $10 \mathrm{~min}$ with $6 \mu \mathrm{l}$ of SSCP loading buffer $(0.2 \mathrm{M} \mathrm{NaOH}, 0.25 \% \mathrm{w} / \mathrm{v}$ each bromophenol blue and xylene cyanol in formamide) and separated on a $6 \%$ native polyacrylamide gel. The sequence data described in this paper have been submitted to $\mathrm{G}$ enB ank under accession numbers A F 020663-A F 020676.

\section{Results and Discussion}

The human MTM 1 gene is composed of 15 exons ranging from 44 to $207 \mathrm{bp}$ (Table 1 ), the last exon been 223 or $1713 \mathrm{bp}$ in length, depending on the polyadenylation signal used. ${ }^{4}$ The predicted sizes of polyadenylated transcripts are about 3.6 and $2.1 \mathrm{~kb}$, compared to the previously reported sizes of 3.9 and $2.4 \mathrm{~kb}$ observed on northern blots. This difference may result from experimental errors in sizing and/or reflects a $5^{\prime}$ extension of the transcript with respect to the cloned cDNA s. This gene covers around $100 \mathrm{~kb}$ (between 96 and $104 \mathrm{~kb}$ ) in the $\mathrm{Xq28}$ proximal region. Exon 11 encodes the predicted tyrosine phosphatase active site and exon 1 is non-coding. Phase 0 introns (uninterrupted codon) are highly predominant (12 out of 13), whilst phase 1 (splice site after the first codon position) accounts for only one intron and phase 2 (splice site after the second nucleotide) is not present. A Iternative spliced transcripts have not been reported so far, but if they exist, they will have a high chance of keeping the same open reading frame as the initial transcripts. Moreover, nucleotide changes affecting splice sites may still give a coding transcript lacking a portion of the protein if they lead to exon-skipping.

A ll of the exon-intron boundaries conform to the A G /G T rule, except for the donor site of exon 10 where a $G C$ is found instead of GT in every patient and normal DNA analysed. This has al ready been described for a few other examples. ${ }^{7} \mathrm{~A}$ polymorphism at position $1314+3$ in the donor site of intron 11 was found, where A or $G$ were equally present in the population, ${ }^{6}$ and both nucleotides fit with the consensus sequence. The intronic sequences flanking the MTM 1 exons and the sequence of the predicted promoter can now be used to derive primers and screen for mutations in patients, 
especially for patients for whom only genomic DNA is available. This has very recently allowed the identification of 79 mutations in 124 patients analysed and confirmed the highly heterogeneous nature of such mutations. ${ }^{6,8}$
We have recently sequenced a full length cDNA clone corresponding to one of the two homologous genes present in Caenorhabditis elegans (unpublished results, Laporte J, 1997). Comparison with the genomic sequence in the $\mathrm{ACeDB}$ database ${ }^{9}$ showed that the

-2707 GAGGCCAGCCATCTTCTCACAGGCCTCCTGCATGATGGGGGGTTGTATGTGTGCAAAATGCAGGGAAGCCTGAAGATTCCTACACACACACACACACAC

-2607 ACACACACACACACACACACACTGAAATGTGAGTGCAGCCCAGCCTGGAAGAGGGCAGGCTCAGTCAAGAATACAGCGATGTCACCAAGGGCAAGGCGG myogenin

-2507 TAACCCCTCCATAGTGTACAACCTIGTTTGITTGTTTGTTTTGAGATGGAATCTCACTCTGTCACCCAGGCTGAAGTGTAGTGGTGCAATCTCAGCTCAC

-2407 TGCAACCTTCACCACCCGGGTTCAAGTAATTCTCCTGCCTCAGCCTCCCGATTAGCTGGGATTACAGGCGCCCACCACCACGCCTGGCTAATTTTTTTGT

-2307 ATTTTTAGTAGAGACGGGGTTTCACCATGTTGGCCAGGTTGGTTTCGAACTCCTGACCTCAAGTGATCCGCCCGCCTCGGCCTCCCAAGGTGCTGGGATC -2207 ACAGGCCTGAGCCACCGCGCCCAGCCCATAGTGTACAACCTTTACA // GGCCTATTATATGCAAGGTATCCCAGGCAGCTGCTGCCCTCCCTCCACCC $1 /$ myogenin

-1807 ATCCCCATTTTCCTCTATCCCTCTGCCCTAAGATTCACAGATACCAGGAATCCAGAGTTATTCAGCAGCCCACCAGGGAGCCTCTCTAGCATGCAAATTT myogenin

TEF1

-1707 ACTGAGCGTGCTTTGAAATTCAGCACAAAAGTGAATGAGATTCAAAGGAGTTCATAGTCTGGGGAGGGGAGTTGGCAGAGCAGACGTGTAAGCAAATGAT

-1607 GACATCAGTACAACAAGAAGGGCTGGGTGGGGAGACTTCT // TTTTTTAATTTTTTTGACACGCAGTCTCGCTTTGTCACACAGGCTGGAGTGCAGT CREB 11

-1007 GGTGCCATCTCAGCTCACTGCAACCTCTCCCTCCCGGGTTCAAGCGATTCTCTTGCCTCAGCTTCCCGAGCAGCTGGTATTACAGACACCTGCCACCACG

-907 CCTGGATAATTTTTTATTTTTAGTAGAGACGAGGTTTCACCATGTCGTCCAGGCTGGTCTCGAACTCCIGACCTCAGGTGATCCGCCTGCGTTGGCCTC

-807 CCAAAGTGCTAGGATTACAGGCGTGAGCCACCGCGCCCGCCCAGATTGTTTGTTTTATTTGATTACACAATGAATTCTCTTCTTGAAGTTTGCCTTTCT HOXD $9 / 10$

-707 TCTCTTTTTCCTGTCCCTTTCTTTTACTGTATCAATAGTTGTCTGACCCAAACCTCAACAAGTAGAAGGAATTTGGACTGAAATGTTTCCGTTCACTA $\mathrm{ER} / \mathrm{C}-\mathrm{fOS}$

-607 AGTCTCAATTGCGTTCTTGGAAAGGTGCTGGCACAGCTGAGGGACACCCCAGCTGTTAGTTGAGTTTGTGAATTGCAGATCCTGCCCCAGAGTCAGTGAA

-507 ATTTCTTTTTCCTIATACTATCTCAACTTTACGCAGCCAACCCTGTGTACCCAATAATAGCTCAATTTAGTGGCATCCGCTAAAGTCTTGTATAGAGAA

-407 GTTTTCCCTCTGGATTTCCCCTTTACTGAAGAAAAATGGGGAGACCCAGACAAGGGTCCCGGGACTACGCTTCCCAGCCGCCTCCGCCCGGCGCCCAGTC AP-2

-307 CAACTTCCCTTACAGGGATGGCCCCTGGCATCTIGGCCCCGCCCATCCCCAGCACCATATTGCGAACTACAATTCCCAGCTGCCTCCATGCGTCGGACCC Sp1 AP-2

-207 TTCAAAATGGGCTTCCCAGCAGCCTCTCGGGCGAAGAGCCCCGCCCTTCGGAGCTGCTCCCCAGGTCGACCCGGCGCACTCTTCCTGCCCCCTGCCCCGT $\operatorname{Sp} 1$

-107 CACGTGATGCAGTCCCGCCAACCGGCACGGGGAGGCGGGCAGCGGGCGGTGGCCGGGGGCGGGCAGGCCGTGGGGGGCGGACCCCAGAGGGGGCGGAGCA

-7 GGGCCCGGCAGCCGAGCAGCCTGGCAACGGCGGTGGCGCCCGGAGCCCGAGGTGGGTGCGCGCTCACGGCTGG

Figure 2 H uman M T M 1 putative promoter. This sequence is to be found in $\mathrm{G}$ en B ank under accession number A F 020663. The exon 1 sequence is shown in bold and the negative numbering on the left is based on the first nucleotide of exon 1 . Two A lu sequences are in italic and the polymorphic CA repeat (DX S9929) is underlined. The TESS database (http://agave.humgen.upenn.edu/tess/) was screened on a string-based search using the homo sapiens subset, and the predicted transcription factors binding sites are underlined with the name of the transcription factor written below. Part of the sequence that lacks obvious features was omitted. 
Table 1 Exon-intron organization of the MTM 1 gene

\begin{tabular}{|c|c|c|c|c|c|c|}
\hline Exona & $\begin{array}{l}\text { Exon size } \\
\text { bp }\end{array}$ & $\begin{array}{l}\text { 3' splice sitec } \\
\text { acceptor }\end{array}$ & $\begin{array}{l}\text { 5' splice sitec } \\
\text { donor }\end{array}$ & & $\begin{array}{l}\text { Intron } \\
\text { phase }\end{array}$ & $\begin{array}{l}\text { Intron size } \\
\mathrm{kb}\end{array}$ \\
\hline 1 & 44 & & GCCCGAG & gtgggtgcgc & 1 & $22-30$ \\
\hline 2 & 73 & ttcttggtag AGTTTCC & - $\quad$ TAAGAGG & gtaagttgaa & 0 & 3.8 \\
\hline 3 & 73 & ttgtttctag ACGTCTC & - ATCACTG & gtaaggacct & 1 & 2.0 \\
\hline 4 & 95 & atctaatag $\mathrm{ACAAAGA}$ & - GGAACG & gtaagtagaa & 0 & 14.2 \\
\hline 5 & 111 & tccattacag GATTCTT & - TTGTAAA & gtaagagatt & 0 & 1.3 \\
\hline 6 & 102 & ttgcccccag GACATGA & - CAGTCTG & gtaaattcca & 0 & 20.4 \\
\hline 7 & 84 & ccttttctag CСАТТАТ & - GAGGCAG & gtaagatgtt & 0 & 2.6 \\
\hline 8 & 150 & ttcctcacag G G CTTGC & - AАTTCCA & gtgagtactg & 0 & 4.5 \\
\hline 9 & 189 & ttaaccatag GTGCTGT & - CAACAAG & gtgagtggac & 0 & 3.9 \\
\hline 10 & 186 & tgtttcttag GCAACAG & - TATCAAG & gcaagtatat & 0 & 7.9 \\
\hline 11 (PTP) & 207 & tctttgtcag CTCGTTT & - TGCATCT & gtragtaaac & 0 & 1.7 \\
\hline 12 & 93 & atttattcag CGAATA G & - AAAACAG & gtaaggaata & 0 & 0.6 \\
\hline 13 & 114 & ttttgtttag ТТСССТА & - AAGACAG & gtgagttaaa & 0 & 3.1 \\
\hline 14 & 177 & ctctctgtag A A G GTTA & - GCAACAA & gtaagtgaag & 0 & 8.2 \\
\hline $15 \mathrm{~b}$ & 1713 & ttctctccag CA GCCGA & & & & \\
\hline
\end{tabular}

aE xons 8, 9, 11, 14 and 15 correspond to exons named respectively $a, b, c, d$ and e in reference 4 ; b $\mathrm{n}$ the additional $2.4 \mathrm{~kb}$ muscle specific transcript, exon 15 is only 223 bp long due to the use of a different polyadenylation signal; 4 cE xon and intron sequences are shown in upper and lower case, respectively; G enB ank accession numbers for the sequence data: A F 020663-A F 020676.

genomic structure is not conserved compared with the human MTM 1 gene and that there is no preferential intron phase.

Because cis elements of a promoter are generally arrayed within a few hundred base pairs of the MR NA initiation site, we determined $2.7 \mathrm{~kb}$ of sequence directly upstream from exon 1 (Figure 2 ). A polymorphism at position - 110 was observed ( $T$ instead of $C$ ) in two patients (out of 60 patients tested) and in two normal X-chromosomes (out of 40 tested). 0 ne of the patients had already a frameshift mutation in exon 2 and the second had a mutation in exon 4 (patient N 1-44 in ref 6 and unpublished data, Tanner SM, 1997, respectively).

In the original description of the cDNA sequence, the location of the translation initiation site had not been determined. M oreover, an open reading frame of $426 \mathrm{nt}$ is present proximal to the first CDNA base. $5^{\prime}$ RACE experiments and numerous CDNA libraries screening with $5^{\prime}$ probes led to several clones starting at position +1 in Figure $2 .{ }^{4}$ RT-PCR using exon 1 primers amplified the expected product while nothing was amplified using primers proximal to position +1 (not shown). M ore recent data using antibodies directed against myotubularin indicate that the endogenous protein is translated starting from the first methionine codon of the published CD NA sequence, corresponding to codon 19 (unpublished results, Laporte J, 1997).

The sequence between position - 370 and the end of exon 1 is very $\mathrm{GC}$-rich $(73 \%)$ and exhibits rare CpG cutter sites (BssHII, Eagl, Narl, Notl, Sacll). It contains several predicted SP1 sites but no TA TA -box or CAAT-box, as is often the case for a CPG island region upstream of a housekeeping gene. ${ }^{10}$ The MTM 1 gene has been shown to be ubiquitously expressed with an additional shorter transcript that uses a different polyadenylation signal in muscle and testis. ${ }^{4} \mathrm{No}$ eukaryotic pol II promoter was predicted by the GRAIL program although the TSSG BCM program ${ }^{11}$ predicted with a very high score (LDF-33.10) a TATA -less promoter in the neighbourhood of exon 1 in the expected orientation, with a putative transcription start site at position +37 of the MTM 1 CDNA. Other transcription factor sites were predicted by the TESS program, ${ }^{12}$ especially three myogenin binding sites, which might be important for muscle-specific transactivation and differentiation. Fifteen putative E-box (CANNTG) elements are present in the predicted promoter sequence and the M yoD transcription factor has been shown to specifically activate muscle genes by binding to the E-box. ${ }^{13} \mathrm{~A}$ s myotubular myopathy seems to be due to a defect in late myogenesis, the regulation of the MTM 1 gene transcription or/and regulation of myotubularin activity might be an essential step toward the complete maturation of muscle fibres.

It is not uncommon that two genes start from the same CpG in opposite directions and several transcripts were reported in the neighbourhood of the MTM 1 gene, ${ }^{14}$ especially XAP83 located proximal. The sequence of the putative promoter did not detect ESTs in $\mathrm{dbEST}$ and no exons were predicted by GRAIL ${ }^{15}$ and $B C M^{11}$ programs, with the exception of exon 1 
Table 2 Characterisation of a new polymorphic CA repeat (DX S9929)

\begin{tabular}{|c|c|c|c|c|}
\hline R epeat & (CA ) 18-24 & $\begin{array}{l}\text { A lleles } \\
\text { CA number }\end{array}$ & $\begin{array}{l}\text { PCR size } \\
\text { bp }\end{array}$ & $\begin{array}{l}\text { Frequency } \\
\%\end{array}$ \\
\hline Primers & $\begin{array}{l}\text { 5' TGTCCTGGA G CCCTGGAG 3' } \\
\text { 5' CGCTGTATTCTTGACTGA GC 3' }\end{array}$ & $\begin{array}{l}24 \\
23\end{array}$ & $\begin{array}{l}210 \\
208\end{array}$ & $\begin{array}{r}1 \\
20\end{array}$ \\
\hline H eterozygosity & $65 \%$ & $\begin{array}{l}22 \\
21 \\
20 \\
19 \\
18\end{array}$ & $\begin{array}{l}206 \\
204 \\
202 \\
200 \\
198\end{array}$ & $\begin{array}{r}4 \\
7 \\
3 \\
54 \\
11\end{array}$ \\
\hline
\end{tabular}

which was predicted, although not precisely, by FEXH BCM program with a score of 7.86 .

A CA repeat is present at position -2624 to -2587 and contains 19 repeats. A nalysis of 118 unrelated Caucasian $X$ chromosomes with flanking primers revealed seven alleles ranging from 18 to $24 \mathrm{CA}$ dinucleotides (Table 2). The predominant (CA ) 19 allele accounts for $54 \%$ of the chromosomes tested. The frequency of each allele is reported in Table 2 and the calculated heterozygosity is $65 \%$. This new polymorphic marker, DXS9929, should prove useful for diagnosis by linkage analysis in familial cases, in combination with previously characterised DXS8377, DXS7423 and DXS1684. ${ }^{16}$ DXS9929 is the closest characterised polymorphic marker from the MTM 1 gene and may be more reliable than for example, DX S8377 which is located around $200 \mathrm{~kb}$ proximal, and was already found to recombine in an XLMTM family. ${ }^{16}$

\section{Acknowledgements}

We wish to thank Christine K retz and V reni Schneider for excellent technical assistance. This study was supported by the Institut $N$ ational de la Santé et de la $R$ echerche $M$ édicale, the Centre National de la Recherche Scientifique, the Centre $\mathrm{H}$ ospitalier U niversitaire R égional, and by grants from the A ssociation Française contre les $M$ yopathies (A FM) and the Swiss National R esearch Foundation (No. 32-043631.95).

\section{References}

1 Fardeau M: Congenital myopathies. In Mastaglia FL \& Walton of $D$ etchant (eds). Skeletal Muscle Pathology. Churchill Livingstone: E dinburgh, 1992, pp 1504-1505.
2 Thomas $\mathrm{N}$, Williams $\mathrm{H}$, Cole $\mathrm{G}$ et al: $\mathrm{X}$-linked centronuclear/myotubular myopathy: evidence for linkage to X q28 D NA marker loci. J Med G enet 1990; 27: 284-287.

$3 \mathrm{Hu} \mathrm{LJ}, \mathrm{L}$ aporte J, K ress W et al: Deletions in X q28 in two boys with myotubular myopathy and abnormal genital development define a new contiguous gene syndrome in a $430 \mathrm{~kb}$ region. $\mathrm{H}$ um $\mathrm{M}$ ol $\mathrm{G}$ enet 1996; 5: 139-143.

4 Laporte J et al ( $G p 1), K$ ioschis $P$ et al (Gp 2), Dahl N ( $G$ p 3): A gene mutated in $X$-linked myotubular myopathy defines a new putative tyrosine phosphatase family conserved in yeast. Nat G enet 1996; 13: 175-182.

5 Fauman $E$, Saper MA: Structure and function of the protein tyrosine phosphatases. Trends B iotech Sci 1996; 21: 413-417.

6 Laporte J et al (Gp 1), Tanner SM et al (G p 2), WallgrenPettersson $C$ et al ( $G$ p 3): Mutations in the MTM 1 gene implicated in $\mathrm{X}$-linked myotubular myopathy. $\mathrm{H}$ um $\mathrm{M}$ ol G enet 1997; 6: 1505-1512.

7 Shapiro MB, Senapathy P: RNA splice junctions of different classes of eukaryotes: sequence statistics and functional implications in gene expression. N ucleic A cids Res 1987; 15: 7155-7174.

8 de G ouyon B, Z hao W, Laporte J, M andel J L, M etzenberg A, Herman G: Characterization of mutations in the recently identified myotubularin gene in twenty-six patients with $\mathrm{X}$-linked myotubular myopathy. $\mathrm{H}$ um $\mathrm{M}$ ol Genet 1997; 6: 1499-1504.

9 D urbin R, M ieg JT: A C. elegans database. D ocumentation, code and data available from anonymous FTP servers at lirmm.lirmm.fr, cele.mrc-Imb.cam.ac.uk and ncbi.nlm.nih.gov..

10 Dynan WS: Promoters for housekeeping genes. Trends G enet 1986; 2: 196-197.

11 Solovyev VV, Salamov A A, Lawrence CB: Predicting internal exons by oligonucleotide composition and discriminant analysis of spliceable open reading frames. Nucleic A cids Res 1994; 22: 5156-5163.

12 Boulikas T: A compilation and classification of DNA binding sites for protein transcription factors from vertebrates. Crit Rev Euk Gene Expression 1994; 4: 117-321.

13 Lassar $A B, B$ uskin JN, Lockshon $D$ et al: $M$ yoD is a sequence-specific $D N A$ binding protein requiring a region of myc homology to bind to the muscle creatine kinase enhancer. Cell 1989; 58: 823-831.

14 Kioschis $P$, Rogner U C, Pick E et al: A 900-kb cosmid contig and 10 new transcripts within the candidate region for myotubular myopathy (M TM 1). Genomics 1996; 33: 365-373. 
$15 X u Y$, M ural $R$, Shah $M$, U berbacher $E$ : Recognizing exons in genomic sequence using GR A IL II. Genet Eng 1994; 16: 241-253.
$16 \mathrm{Hu}$ LJ, Laporte J, Kioschis $\mathrm{P}$ et al: $\mathrm{X}$-linked myotubular myopathy: refinement of the gene to a $280-\mathrm{kb}$ region with new and highly informative microsatellite markers. H um G enet 1996; 98: 178-181. 